\title{
DESAFÍOS DE CONOCIMIENTO EN LOS MOVIMIENTOS POPULARES RURALES DE ARGENTINA
}

\section{DESAFIOS DE CONHECIMENTO EM MOVIMENTOS POPULARES RURAIS DA ARGENTINA}

\section{KNOWLEDGE CHALLENGES IN RURAL POPULAR MOVEMENTS IN ARGENTINA}

\author{
Alvaro Javier Di Matteo ${ }^{1}$
}

\section{RESUMEN}

El artículo recupera problemas y desafíos construidos por los movimientos populares rurales de Argentina en su praxis política y profundiza en los aspectos relacionados a las necesidades de formación que emergen de aquellos. Un proceso de recampesinización, asociado a una relativa madurez de los procesos de organización y a la resistencia frente al modelo hegemónico, sirve de apoyo a intencionalidades formativas diversas. En este trabajo nos detendremos en dos de ellas. Por una parte, a la construcción de la memoria y la identidad colectiva, como proceso de recuperación y reelaboración del pasado común ante los desafíos del presente, y por otra, a los ensayos de actividades económicas que potencian el trabajo campesino y lo inscriben en proyectos que buscan contrariar el orden dominante.

PALABRAS CLAVE: Memoria; identidad; campesinado; alternativas económicas, diálogo de saberes.

\section{RESUMO}

$\mathrm{O}$ artigo recupera problemas e desafios construídos pelos movimentos populares rurais da Argentina em sua práxis política e aprofunda os aspectos relacionados às necessidades formativas que dela emergem. Um processo de "recampesinización", associado a um relativo amadurecimento dos processos organizacionais e à resistência ao modelo hegemônico, serve como suporte a diversas intenções formativas. Neste trabalho vamos considerar dois deles. Por um lado, para a construção da memória e da identidade coletiva, como um processo de recuperação e reelaboração do passado comum frente aos desafios do presente e, por outro, aos ensaios das atividades econômicas que potencializam o trabalho camponês e o inscrevem em projetos que buscam contrariar à ordem dominante.

\footnotetext{
${ }^{1}$ Doctor con orientación en Ciencias Humanas y Sociales de la Universidad Nacional de Luján y Licenciado y Profesor en Ciencias de la Educación por la misma Universidad. Es docente del Área de Pedagogía de la Educación de Adultos en movimientos sociales, División Educación de Adultos. E-mail: javidimatteo@yahoo.com.ar
} 
PALAVRAS-CHAVE: Memória; identidade; campesinato; alternativas econômicas, diálogo de conhecimento

\section{INTRODUCCIÓN}

En América Latina actual, el lugar de las luchas campesinas es central. Lo ha sido a lo largo de la historia, aunque en las últimas décadas, signadas por los intentos de construcción de una hegemonía neoliberal en nuestras sociedades, han alcanzado un nuevo protagonismo, e incluso se constituyen en referencias, tanto intelectuales como simbólicas, para sujetos urbanos, aún más allá de las geografías americanas.

Argentina, una de las sociedades más urbanizadas de la región, no ha sido ajena a un proceso de reactivación de las luchas campesinas. Tras la salida de la última dictadura, todos los procesos de afirmación popular comenzaron a renovarse, intentando superar los efectos de la represión, destacadamente, la pérdida de militantes políticos dinamizadores de procesos organizativos, pero también los efectos disciplinadores sobre las camadas populares. Por otra parte, nuevos elementos de contexto acelerarán el surgimiento de organizaciones y el ritmo de las luchas.

Las iniciativas políticas de los años 90, relacionadas al Consenso de Washington, implicaron readecuar nuestras economías al modelo exportador primario, ese que los manuales liberales reservan para las sociedades atrasadas, de modo de superar su atraso apoyándose en sus "ventajas relativas". Pero esta vez, una economía reprimarizada, debilitando los esbozos de industrialización, y con mayor protagonismo de actores más allá de nuestras aristocracias nativas, esas que en Argentina son reconocidas con el nombre de "oligarquía": esta vez grupos financieros y empresas trasnacionales son convocadas a ese "ajuste estructural" (TEUBAL, 2008). El proceso de transformación de la actividad primaria incluye un movimiento de ampliación de los territorios integrados a la economía mundial durante el siglo 20, que afecta de manera directa al entramado comunitario campesino e indígena, así como otro conjunto de fenómenos como la desestructuración de ciertas economías locales, con las que el campesinado se articulaba de distintas maneras. Los sujetos dominantes del mundo rural se renuevan, así como las prácticas y lógicas económicas mientras que los procesos de concentración de 
la tierra se acentúan ${ }^{2}$, a la par de la ausencia de cualquier tipo política pública democratizadora tendiente a favorecer el acceso a la tierra por parte de pequeños productores, campesinos y trabajadores sin tierras.

A los efectos de este trabajo alcanza con señalar que la avanzada neoliberal sobre el mundo rural y sobre sus sectores populares, especialmente en lo que concierne a la adecuación de la actividad rural a cadenas de valor trasnacionalizadas, junto a la ausencia de políticas de acceso a la tierra para las y los trabajadores rurales, son factores influyentes, no únicos, de un proceso de crecimiento de las luchas sociales rurales, que con sus particularidades, se encuentran activas, en crecimiento y han experimentado un proceso de complejización de sus prácticas políticas en todo el territorio del país. Nuestra afirmación acerca de la existencia de más de un factor y más de una causa de los procesos de organización obedece a un reconocimiento muy elemental de la complejidad de las realidades de nuestros países, de la propia Argentina y de los procesos de organización popular en general (RETAMOZO, 2012; 2018). En todo caso, los elementos que nombramos no pueden dejar de ser considerados en el conjunto de los elementos que contextualizan la (re)emergencia de las organizaciones y movimientos campesinos que habrá que especificar para cada realidad concreta.

Desde nuestro conocimiento de esa realidad nacional, que es, por supuesto, fragmentario, limitado, provisorio (CASTORIADIS, 1990), ensayamos una tarea de reconocimiento y reconstrucción de iniciativas político-pedagógicas que suelen encontrase en los movimientos de nuestro país, con mayor o menor énfasis, con distintos niveles de desarrollo de cada una de ellas; iniciativas que emergen de los desafíos que los movimientos se trazan como respuestas a las situaciones que atraviesan y en dirección a los proyectos alternativos que construyen en su caminar.

En este trabajo presentaremos un acercamiento a dos de esas intencionalidades. Por una parte, un movimiento hacia la afirmación de las identidades campesinas, muchas veces relacionadas a procesos de afirmación de identidades étnicas, movimiento que se enfrenta a procesos de interdicción de saberes y significaciones tradicionales. En segundo lugar, un movimiento de reelaboración de la tarea económico productiva de las y los campesinos, donde las posibilidades de arraigo y mejora de

\footnotetext{
2 Aunque con nuevas racionalidades, incluyendo el acaparamiento de tierras a través de mecanismos de alquiler de extensiones inmensas para construir escalas acordes a las tecnologías y manejos puestos en juego para la siembra directa (GRASS; CÁCERES, 2017).
} 
las condiciones de trabajo y de vida se enlaza con el proyecto político más amplio, de transformación de las formas de trabajo y de vida rural y comunitaria.

Centramos la exposición en estas dos intencionalidades políticas describiendo como se expresan en algunas experiencias del país y luego de esas descripciones nos abocamos a analizar su significado en términos de desafíos de conocimiento, esto significa, poniendo en relieve las tareas de

formación y de investigación que campesinas y campesinos se dan con vistas a fortalecer sus prácticas.

Cabe destacar que este trabajo es posible porque está apoyado en un recorrido de investigación de carácter colectivo, realizado en el marco del Programa de investigación "Movimientos Populares, Educación y producción de conocimiento"3 . Las investigaciones cobijadas en ese Programa aportan toda la información de carácter empírico compartida en este texto. Las mismas fueron desarrolladas en el marco de un trabajo acordado con las organizaciones y movimientos campesinos que se mencionan en las citas textuales de distintos trabajadores y trabajadoras rurales, presentadas a lo largo del texto. En diálogo con esas organizaciones del campo se busca construir objetivos de investigación que resulten útiles a sus iniciativas y proyectos. En términos metodológicos, la información construida es el resultado de un trabajo de campo extendido en el tiempo a partir fundamentalmente de observaciones participantes y entrevistas en profundidad.

\section{LA MEMORIA Y LA IDENTIDAD EN LAS LUCHAS CAMPESINAS E INDÍGENAS}

\section{"articular históricamente lo pasado no significa conocerlo «tal y como verdaderamente ha sido». Significa adueñarse de un recuerdo tal y como relumbra en el instante de un peligro", (Walter Benjamin)}

Buen número de los procesos de organización y de lucha requieren reconstruir el pasado y reflexionar sobre él. Un pasado que ofrece elementos para afirmar identidades, pero también aporta indicios y apoyaturas para construir proyectos colectivos. Sabemos que la indagación en el pasado es siempre una actividad que debe leerse desde las necesidades del presente y en ese sentido son muy

\footnotetext{
${ }^{3}$ Radicado en el Departamento de Educación de la Universidad Nacional de Luján, Argentina.
} 
apropiadas las palabras de Benjamin. El pasado es siempre un asunto relativo porque, efectivamente, ¿qué cosa del pasado necesita ser recordada? El pasado está presente, y si lo está es porque es útil para algo hoy, y por eso es seleccionado: es parte de una "tradición selectiva" (WILLIAMS, 1980).

a) En esa búsqueda del pasado hallamos distintos ejercicios. Existe uno relacionado a la defensa de los territorios, cuando se hace necesario recuperar la memoria particular y local. Especialmente en situaciones de amenaza sobre posesiones campesinas, el ejercicio de resistencia es inseparable de un proceso de afirmación de una memoria que da cuenta de la presencia en el lugar por generaciones, reconstruyendo genealogías, recuperando usos y prácticas territoriales, identificando las marcas de esas prácticas en los sitios, poniéndole un nuevo valor a lo que antes era simplemente objetos del afecto: fotografías, cartas, documentos son también pruebas de la presencia campesina y recursos para rememorizar. La memoria es el ejercicio indispensable para argumentar frente al aparato judicial, frente a actores locales, y también internamente, hacia adentro del colectivo social, como ejercicio de autoafirmación del derecho colectivo.

b) Las luchas por la tierra, por lo general, no se agotan en un solo momento, se sostienen en el tiempo. En ciertos sitios, se resiste a las amenazas de desalojo de las posesiones, de uso familiar o comunitario, y al avance más general de las prácticas económicas dominantes. En otros lugares, oucrren procesos de recuperación de territorios indígenas. En otros, se lucha por la tierra para salir de situaciones de carencia de tierra, lo que suele resolverse a través de la mediería o el alquiler. Son procesos extensos, con avances y retrocesos, con momentos de lucha directa en los territorios, momentos de negociación o de movilización, con instancias de construcción de la propia autoorganización. Las y los campesinos construyen o se suman a procesos de organización y allí emerge como tarea central afirmar la legitimidad de la lucha. Es necesario decir que la lucha es correcta y justa, desarmando los discursos dominantes que la descalifican. Frente a esas necesidades, la mirada también se dirige hacia el pasado.

La reconstrucción de los procesos de lucha en torno a los territorios, las expropiaciones, las recuperaciones, los saqueos sistemáticos de bienes comunes, se recuperan como parte de construcción de la legitimidad de la lucha social campesina. Es una historia apoyada en el genocidio de las y los habitantes originarios y de desarrollo de una clase oligárquica a costa de la apropiación de la tierra, los bosques y el agua, y de la explotación de fuerza de trabajo de origen campesino; en esa historia 
relativamente reciente ${ }^{4}$ (Bartolomé, 2003, Grosso, 2014), los ejercicios de memoria encuentran también donde apoyarse.

c) Hurgar en la memoria tiene como objetivo también defender "el modo de vida campesino", frente a ese discurso prevaleciente que pone a las comunidades como sinónimo de atraso, de inviabilidad, lo que está más allá de los imaginarios y prejuicios colectivos: permea la mentalidad de jueces y policías, de autoridades públicas y funcionarios (BARBETTA, 2012), de maestros y agentes de salud y que afectan tanto la vida cotidiana como la lucha colectiva.

Defender los modos de vida hasta entonces practicados implica recuperar el conjunto de prácticas y de relaciones sociales, con frecuencia recordadas con afecto, como parte de la vivencia familiar e individual, pero esta vez, recuperarlas en su dimensión social y cultural, enfrentadas a una narrativa del progreso y el desarrollo que comenzó a mostrar señales de agotamiento, pero que aún así persiste. $\mathrm{Y}$ en ese sentido, recuperar esas prácticas que estaban dadas e indagar acerca de los mecanismos que las desestabilizaron e interrumpieron, poniendo un ojo crítico sobre las estigmatización y sobre los procesos sociales, no solamente ideológicos, sino también económicos, institucionales, etc.: el trabajo "para afuera”, el clientelismo político, el estímulo del consumo y el uso generalizado de dinero, ciertas formas de religión, la escolaridad obligatoria, son ejemplos de esto que afirmamos.

d) Entre ese conjunto de prácticas interdictas, relativamente suspendidas, desvalorizadas, se encuentran las prácticas económicas tradicionales, leídas en la actualidad desde claves novedosas. Por una parte, son las que permiten autonomía respecto de las relaciones sociales y laborales que impone el mercado y respecto de las distintas formas del clientelismo político, por otra; se revalorizan en la medida que ofrecen producciones sanas en comparación con las que prevalecen en la producción

\footnotetext{
${ }^{4}$ Si bien la invasión del territorio de la actual Argentina por fuerzas españolas remite a más de 500 años, esta afectó fundamentalmente a las poblaciones de centro, oeste y noroeste del país, vinculadas al sistema de intercambios andino, que fueron en buena medida integradas a la economía colonial, articuladas a las necesidades del sistema extractivo de la plata, en el altiplano de la actual Bolivia, conocido como Alto Perú. Las poblaciones de la zona pampeana fueron desplazadas hacia el sur patagónico, y las poblaciones del noreste permanecieron en sus territorios al amparo de los bosques del Gran Chaco. Recién en la segunda mitad del siglo XIX el Estado Nacional avanzó violentamente sobre esos territorios que permanecían bajo control indígena, dando lugar a la ampliación de la frontera agropecuaria e incrementando las explotaciones, el poder de los latifundistas e impulsando aquello que Grosso designa como el "blanqueamiento" de la población: la negación del pasado indígena, un fuerte proceso de interdicción de las identidades. Tras ambos momentos de invasión y a pesar de hacerlo en condiciones adversas, siguieron existiendo y reproduciéndose las comunidades originarias.
} 
capitalista industrializada, finalmente, permiten organizar el trabajo de manera campesina, con los ritmos y tiempos propios, con racionalidades que no están atadas al ordenamiento temporal rígido ni identifican valor y precio:

Por un hecho cultural nosotros hemos vivido siempre en comunidad, compartiendo el territorio, compartiendo la aguada y compartiendo el trabajo también: "yo te ayudo y vos me ayudas, vos cosechas y yo tengo, yo cosecho y tu tienes", hemos sido un pueblo... solidario. Nos uníamos, en todas las actividades, siempre había... la minga. Igual cuando se carneaba: "decile que me preste", al vecino, "carneas vos y yo te devuelvo". Y eso no era "si tienes plata llevas", como es hoy. Y eso va cambiando y uno se va encontrando con un modo de vida, van imponiendo un modo de vida muy diferente (Paulo Aranda, MOCASE VC).

Antiguamente se trabajaba mucho la tierra. Yo nací en una ruca mapuche, de piso de tierra. Conocí lo que era el tamango. No usábamos botas, no usábamos zapatillas. Nuestra historia era más rica que hoy. Así que eso está para rescatar, para que vean los jóvenes hoy por hoy. Se servían unos con otros, se ayudaban. Se tiene que valorar, se tiene que recuperar acá en nuestra comunidad. Siempre se vivió de los cultivos, de la cosecha: de la alverja, la haba, el trigo, de trigo se hacía el ñaco casero, se trabajaba mucho con la piedra de moler, se hacía mucho lo que es el mote, el merquel, el jacó, y ahí mismo se compraba el trigo, la alverja, no íbamos a comprar a otro lado, se compraba todo en la comunidad, trabajaban mucho con el carro, con el buey... (Liria Trupán, Comunidad Mapuche Cayulef, MTE de Neuquén)

Esa racionalidad campesina, muchas veces debilitada para desarrollar procesos de subordinación al mercado, en algunos casos severamente interrumpida, a veces recordada como vivencia infantil o como añoranza de las abuelas y abuelos, las madres y los padres, es observada también por trabajadores rurales que se encuentran más mercantilizados, con curiosidad, con interés y a veces con nostalgia.

e) la afirmación de la identidad indígena corre una suerte paralela a la de la identidad campesina: nos encontramos en medio de un proceso de reafirmación de identidades e incluso de "reetnización" por la vía de la recreación de identidades. En algunos casos, identidades debilitadas se afirman a nivel del trabajo en los campos de la cultura: en la educación, el arte, el lenguaje. Asímismo, se tornan cruciales los de la organización política y la actividad económica, cuestiones que retomamos más adelante.

Bartolomé propone una historización de procesos de "etnogénesis. Los procesos de organización de las comunidades tienen una revitalización decisiva a partir de la década de 1960 provocando un efecto de alteración de las significaciones negativas acerca de lo indígena. 
Nos encontramos ante procesos que podríamos considerar de reetnización, derivada de la experiencia de participación política adquirida en los años anteriores y mediada por la influencia de las organizaciones etnopolíticas, que contribuyeron a dignificar lo étnico y otorgarle un sentido positivo a la condición indígena. Se desarrollaron así procesos sociales de identificación que ahora expresan la emergencia de nuevas identidades, asumidas como fundamentales por sus actores, dentro de contextos históricos y contemporáneos en los cuales se mantienen fronteras entre grupos percibidos como diferentes. (BARTOLOMÉ, 2003 , p. 10 , negritas en el original)

Desde algunas perspectivas campesinas, que inicialmente no se identifican como pueblos originarios, y tras un trabajo de reflexión e información, se afirma que los pueblos indígenas vivían en el territorio sin dañarlo, podían valorar su biodiversidad, lo apropiaban de manera compartida, implementaban prácticas de reciprocidad, se proponían fortalecer la comunidad y desplegar la vida antes que concentrar poder y riqueza; fueron expulsados, explotados, agredidos material y simbólicamente. Su presencia no encajaba en el esquema de dominación en ascenso. No es extraño que emerja la pregunta por la continuidad de la experiencia propia con la de las comunidades indígenas, tras tantos parecidos sustanciales, sostenidos en prácticas, hábitos, sensibilidades y saberes. Parecidos que incluso se proyectan sobre la estigmatización y el destrato recibido:

Y dentro del movimiento hemos encontrado muchos valores, como nuestra propia identidad como pueblo. Que a veces nosotros nos parecía que no era nuestro origen, como que no lo aceptábamos, porque siempre en la escuela hablaban del indígena que era el malo; más identificados como los indios, los brutos, los negros, los rebeldes. Y después hemos ido aprendiendo quién era el malo, porque es como está pasando hoy con nosotros: hoy nosotros somos los malos porque estamos defendiendo la tierra, no le queremos entregar a los empresarios, nosotros somos los usurpadores, nosotros somos los que estamos robando. (Paulo Aranda, MOCASE VC)

Permanecen además algunas prácticas económicas y de apropiación del territorio a las que Paulo se refiere, el uso compartido de los recursos, el uso compartido del bosque, las reciprocidades horizontales, intercambios no mediados por el lucro, y muchas veces ni siquiera por el dinero, la "minga". También esa permanencia es afectada por distintos factores sociales especialmente los

\footnotetext{
${ }^{5}$ En términos generales se habla de minga como trabajo colectivo, un evento en el que todos acuden a realizar un trabajo que es beneficioso para todos, o bien, que es beneficioso para alguien en particular, que, en ese caso, retribuye al resto con comida y ofrece alguna celebración. En ese caso la retribución suele incluir además el asumir una deuda moral con quienes participaron. Para el caso de las Yungas bolivianas, Alison Spedding (1994) describe esos intercambios y deudas como un
} 
relativos a la expansión de las relaciones mercantiles capitalistas, nuevamente, sobre todo en el siglo 20 (volvemos al mismo en el apartado siguiente).

A la par de esas prácticas y usos se ponen en práctica conocimientos (y procesos de transmisión de conocimientos) considerados ancestrales, íntimamente ligados al entorno natural: la obtención de hierbas medicinales, el uso apropiado (sustentable) de la madera, la recolección de alimentos, y ligados además a prácticas culturales y saberes originadas en tiempos remotos, en procesos que dan cuenta de una autonomía significativa respecto de las prácticas culturales dominantes: las formas de cura, la magia, los dones, la religiosidad. Las relaciones no mercantilizadas, así como los procesos de participación colectiva, entre iguales, constituyen valores propiciados en el desarrollo de la organización campesina, pero también pueden rastrearse en la historia, como cualidades presentes en el mundo indígena, el de los "antiguos", y en la historia más reciente vivida o trasmitida por abuelos y padres.

Al mismo tiempo, la afirmación de la identidad indígena es fundamental en el sentido de legitimar la presencia campesina en los territorios, porque pone en cuestión, con mucha claridad, el problema de la propiedad de la tierra y las sucesivas desposesiones propias de la dinámica colonial y luego, la del desarrollo capitalista de la mano del Estado Nación. A la vez, constituye un recurso jurídico más, en la reivindicación de la tierra en términos de regularización bajo una forma de uso comunitario que, como ya dijimos, acompaña los valores que movilizan a la organización.

En estrecha relación con esto último, la identidad indígena contribuye a afirmar una relación con la tierra a partir de una conceptualización renovada: la que incluye las nociones de territorio y de uso colectivo de territorio, de soberanía alimentaria, reforma agraria y biodiversidad.

Permite, además, empalmar con propuestas de "desarrollo" o potenciación de la economía comunitaria como la agroecología, que a la vez que colaboran con la autonomía de las comunidades a partir de prácticas económicas de autorreproducción, legitiman la presencia y el valor económico del campesinado como "sujeto económico" existente y no como resabio del pasado. Una actividad económica que se construye sobre dos valores que comienzan a ser reconocidos en otros sectores

sistema complejo y estrictamente contabilizado basado en dos prácticas llamadas ayni y minka, centrales en la organización del trabajo campesino. 
sociales (producción respetuosa del ambiente y alimentos sanos) que ganan reconocimiento social, más allá de la importancia que estos valores tienen para las trabajadoras y los trabajadores rurales.

e) Como decíamos antes, todo un proceso de imposición colonizadora, en el sentido que es definido por Segato, todo un "frente colonial/estatal, empresarial, mediático, cristiano" (SEGATO, 2014) se despliega más allá de la violencia ejercida por las fuerzas coloniales siglos atrás o por el Estado Nacional, más cerca en el tiempo. La segunda intervención militar sobre territorios indígenas, avanzado el siglo 19 o bien ya iniciado el 20, con el despliegue territorial del Estado Nacional, con su impronta homogenizadora, que afecta a las comunidades indígenas tanto como al campesinado criollo a través de sus mecanismos de integración: escuela, sistema de salud, servicio militar, a la par que el desarrollo capitalista y la conquista territorial requieren que el campesinado se distancie de sus prácticas más autónomas y ponga sus brazos a disposición "del progreso".

Los hechos no se dan mecánicamente, sino que con las exigencias, las particularidades y ritmos de cada región. Un proceso de subordinación cada vez mayor caracteriza la experiencia del campesinado durante el siglo 20.

No estamos hablando solamente de relaciones económicas, sino además de un conjunto de elementos simbólicos e institucionales que entran en juego. Es el momento de ampliación de las iniciativas estatales, de la acción progresiva de los medios de comunicación, especialmente de las radios locales, de la intensificación de las relaciones salariales y también de la articulación de las prácticas productivas en relaciones de subsunción al capital. De manera simplificada podemos decir que las prácticas de autoconsumo y producción diversificada de los alimentos necesarios, pero también de los tejidos, los muebles, los "remedios", etc., se reconvierten en prácticas subsumidas al mercado, donde lo central está en obtener ingreso por la venta de algunos productos o la salida del predio para buscar ingresos y abastecerse por la vía del mercado. Las relaciones comunitarias, en especial las reciprocidades que las caracterizan, son debilitadas, en tanto el mercado individualiza las transacciones. En el plano cultural se pasa de un modo de reproducción de la cultura con altos niveles de autonomía: en la producción y transmisión del saber religioso, técnico, etc., a un modo de vida con creciente presencia de escuelas y medios de comunicación.

En ese movimiento histórico la experiencia campesina pierde niveles de autonomía respecto del orden dominante. Lo hace muchas veces resistiendo o haciendo permanecer algunos elementos: tanto prácticas como significaciones. 
Pongamos dos ejemplos. El retroceso de la práctica de la quichua es, de acuerdo a variados testimonios que recogimos en el MOCASE-VC, constituye una de las pérdidas sociales más importantes del siglo 20. En esa pérdida mucho tuvieron que ver las agencias oficiales, especialmente las escuelas. De todos modos permanece, siendo hablada por algunas personas de cada comunidad. Para distintos integrantes del MOCASE VC que no hablan quichua, lo esperable sería ser "quichuistas", si la transmisión de la lengua no hubiera sido interrumpida.

qué les han hecho a nuestras propias comunidades, cómo las han despedazado pero cómo no han podido desaparecer (...) ...una época del éxodo rural donde muchísimos compañeros han venido expulsados del campo, han venido aquí a las villas miserias en Buenos Aires, en Rosario (...) Si, nosotros pensábamos, en algún momento no nos callábamos y seguíamos la

solidaridad de nuestros pueblos originarios seguramente no nos hubieran despedazado, porque hubiéramos estado con una identidad, que tampoco hubiéramos negado nuestro existir como comunidades. Entonces ahí sí nos sentimos culpables... nos sentimos culpables de que una generación por ejemplo la de mis padres han sido tan... no se cómo buscarle una palabra exacta, han sido tan callados, tan apretados, han sido tan manoseados y vivían en una nube de susto permanente que hasta bueno... quizás en el pensamientos de ellos: "si yo me pongo a enseñarle quichua a mis hijos"... y bueno... estaba la amenaza permanente. El chico es maltratado en la escuela que terminaba de última siete años en la escuela sin aprender nada. (Roque Acuña, MOCASE VC)

Como se observa en la cita, a ese proceso concurren otros factores, uno de ello, la presión sobre las posesiones y la expulsión de muchas familias. La escuela como factor de interrupción del proceso de transmisión de prácticas sociales tradicionales se repite en otras geografías.

Uno tiene la esperanza que los chicos nuestros sean ellos mismos el educador (...) No se respeta el kimun que tenemos, la sabiduría que tenemos. Cuando yo fui a la escuela, tenía 9 o 10 años ahí recién... yo no sabía hablar el castellano, sabía solamente hablar el mapudungun, así que aprendí el castellano... pero también sufrí, el docente no entendía por qué yo no podía hablar el castellano. (Teresa Tripelaf, Comunidad Mapuche Linares - MTE Neuquén)

Entrevistando a esa autoridad comunitaria mapuche en el sur de Neuquén, en territorios patagónicos, ella daba cuenta de su propia labor siendo joven como promotora de salud, contrariando las prácticas sanitarias de su propia comunidad, e imponiendo estrategias de control poblacional inconsultas, que afortunadamente fueron discutidas por las vecinas de entonces.

En ese sur patagónico hallamos también esa reflexión que es fruto del ejercicio de la mirada hacia la historia para construir herramientas para la acción conjunta: 
(los mapuche) eran exitosos en la agricultura, hasta se hacía comercio con la agricultura, había una economía totalmente sólida y firme... de tener una economía a través de la agricultura, la ganadería y la recolección, como siempre se hizo en el mundo mapuche, que hasta hoy se sigue haciendo, pasamos por una decisión política del momento a ser mano de obra. Entonces dejamos todo, dejamos la huerta, la ganadería porque teníamos que trabajarle a alguien (Ariel Epulef, Comunidad Mapuche Curruhuinca - MTE Neuquén).

La decisión política a la que hace referencia el referente mapuche incluye, en su lectura, la imposición de la religiosidad cristiana y el trabajo dependiente como condiciones para el acceso a status de "buena persona".

f) un sujeto que viene sumándose o desarrollando proceso de organización y movilización está constituido por familias de origen boliviano, que tienen un fuerte protagonismo en la producción hortícola en las periferias de las grandes y medianas ciudades, y una presencia importante en regiones de producción intensiva de frutos u otros alimentos, como es el caso de la cebolla. Se trata de producciones muy implicadas en cadenas de valor mercantiles, con una fuerte subordinación económica a actores con mayor poder relativo, más allá de la diversidad de situaciones que se atraviesan (arriendo, mediería, trabajo a destajo, trabajo por jornal, etc). Es notable que la identidad boliviana, el carácter de "paisano" de la gran mayoría de los integrantes de estas experiencias juega un papel en el proceso de construcción de las organizaciones. Quienes participan de ellas con intencionalidad de potenciar esos procesos observan elementos de las tradiciones y de la cultura que están activos y se preguntan por las razones por las que lo indígena no emerge con mayor fuerza y por la potencialidad de procesos de reetnización.

Las prácticas económicas intensivas, mercantilizadas, y el carácter subordinado de los procesos económicos (carencia de tierras, dependencia de porveedores de insumos, dependencia de los acaparadores de mercado) alejan a estas familias de las prácticas más autónomas que caracterizan al campesinado. Queda por verse si los procesos de organización recrean otras economías posibles y qué papel pueda tener en ese proceso la recuperación de saberes y elementos identitarios, presentes o disponibles es un pasado menos sujeto a las relaciones de mercado propias del capitalismo actual.

Por otra parte, un sector de productores, integrados de mejor manera al mercado a lo largo del siglo 20, a partir de contar con tierras, aunque expuestos a los avatares de la economía y de la política económica, se sumaron con entusiasmo a esquemas productivos apoyados en insumos, inversión en 
tecnologías, intensificación de las producciones, propagado por las usinas dominantes. Se encuentran este momento, en algunos casos, ellos mismos o sus hijos y nietos, revisando esa inserción subordinada a cadenas de valor que no controlan y que por momentos conducen a la ruina y la desesperación. La opción por prácticas de agroecología en escenarios de la pampa húmeda deja de ser una práctica aislada para ganar número y principios de autoorganización ${ }^{6}$ (renama).

Nuevamente, allí emerge el reencuentro con saberes del pasado, con el modo de hacer previo a la "revolución verde", con formas de razonar e intervenir en los entornos productivos que realizaban abuelas y abuelos y que fueron descalificados por las usinas dominantes, especialmente por los portadores del saber técnico-científico agropecuario.

\section{LA MEMORIA Y LA IDENTIDAD COMO DESAFÍOS DE CONOCIMIENTO}

En el marco de esos procesos descriptos es donde el trabajo en torno a la memoria histórica toma valor pedagógico. Frente a las debilidades del campesinado que se señalan, la contrapartida es reconstruir esa otra mirada posible. La construcción de otra mirada está relacionada al desarrollo de iniciativas de formación, que facilitan otros modos de ver las cosas o que legitiman intuiciones y sensibilidades existentes. El trabajo pedagógico relacionado a la memoria histórica no se reduce a aportar al reconocimiento y la construcción de un sujeto colectivo; el trabajo sobre la memoria y la acción político pedagógica que supone ese trabajo, activan significaciones acerca de las características de esa experiencia campesina que sirven de crítica a las tendencias dominantes y al desarrollo de propuestas para su superación.

El trabajo de campesinas y campesinos, su trabajo político-cultural y pedagógico, involucra revalorizar algunas prácticas ancestrales y tradicionales, restituirles su valor y en algunos casos hacer el esfuerzo por recuperarlas porque "se han perdido". Supone también reafirmar algunas ideas y desarmar otras. La construcción de memoria colectiva es un desafío formativo. Significa adentrarse

\footnotetext{
${ }^{6} \mathrm{Se}$ puede leer en http://www.renama.org/, "La Red Nacional de Municipios y Comunidades que Fomentan la Agroecología está formada por agricultorxs, técnicxs agropecuarixs, municipios, entes gubernamentales, organismos académicos y científicos, y organizaciones de base, con el objetivo de intercambiar experiencias y conocimientos para la transición hacia la agroecología del sistema agroalimentario."
} 
en los procesos de construcción de esa memoria y hacer de ella lo que Tapia describe con precisión: "subjetividad íntima e intersubjetividad compartida". Los ejercicios de memoria se enfrentan a las significaciones culturales dominantes, desarmando los estereotipos respecto del campesino y del "indio" y desnaturalizando las relaciones sociales capitalistas y sus significaciones y prácticas centrales: sobre el trabajo, el consumo, el tiempo, los vínculos, entre otras.

Y esa tarea es necesariamente dada en los planos individual y colectivo porque sólo se alcanza una afirmación identitaria colectiva a través de procesos de subjetivación que necesariamente pasan por la reflexión individual. Y lo inverso es igual de cierto, no pueden esperarse procesos subjetivos individuales cuando no hay un actor social colectivo movilizando los significados en juego.

Por una parte, la identidad colabora con la intención de potenciar al sujeto a partir de su autovaloración. Cada campesina y cada campesino es portador de una cultura que es valiosa, que ha sido amenazada y que sobrevive a partir de una actitud de resistencia y en virtud de ser valorada y defendida por los sujetos que la portan. También hay cosas a problematizar, pero esas cosas no provienen del pasado indígena, sino fundamentalmente de las iniciativas dominantes, coloniales o modernas, que afectaron a los sujetos y su cultura.

El proceso de comunicación y de construcción y transmisión de saberes no letrados: conocimientos y lenguajes sin status político desde el punto de vista del poder y la cultura dominante: el lenguaje, los elementos poéticos contenidos en el discurso popular, los momentos/espacios de intercambio en la familia, la producción artística (la música especialmente, pero también los tejidos, las comidas, etc.) y la revalorización de las particularidades locales expresadas alrededor de estos elementos. Estos conocimientos y prácticas culturales también se revalorizan y legitiman por su articulación con la experiencia ancestral o tradicional, por el hecho de ser resultado de una experiencia humana de largo aliento.

A fin de cuentas, los procesos de reconstrucción del pasado, de conformación de una memoria colectiva son procesos selectivos donde ponemos en juego nuestra capacidad de darle forma no sólo al pasado, que a fin de cuentas "ya pasó" sino, sobre todo, al presente, que es el lugar desde donde indefectiblemente miramos el pasado. La construcción de una identidad campesina e indígena es entre otras cosas, una clave de lectura del pasado y del presente y se presenta como proyecto, y, en ese sentido, nos parecen muy útiles las consideraciones de Luis Tapia: 
La memoria es como el fondo histórico vuelto subjetividad íntima e intersubjetividad compartida. La memoria se vuelve estructura de rebelión sobre todo cuando contiene elementos de autonomía y libertad colectiva como ejes articuladores que permiten vincular la presencia selectiva del pasado con un horizonte de acción.

Entre la memoria y el proyecto está la cultura en tanto valores, principios y fines que, por un lado, seleccionan en la complejidad de los hechos aquello significativo para la comunidad o la colectividad, de tal modo que son los núcleos de producción de sentido de lo vivido y de lo que se vislumbra como posible y deseable. Nociones de justicia, derechos, soberanía, nación, comunidad, dignidad pueden operar como organización de la relación memoria-proyecto.

Es clave el modo en que se articulan memoria y proyecto. Un proyecto sin memoria no jala fuerzas del mismo modo y con la misma intensidad que cuando lo tiene. (TAPIA, 2008, p. 74)

La reconstrucción de esas memorias dispersas, su apropiación por colectivos: organizaciones, movimientos, comunidades, su revisión y recreación para escenarios actuales es parte de una tarea pedagógica.

\section{LAS PRÁCTICAS ECONÓMICAS EN ORGANIZACIONES CAMPESINAS E INDÍGENAS}

porque tener animales y huerta te hace autónomo (Patricia, Comunidad Curruhuinca, MTE de Neuquén)

La vida productiva de las familias campesinas, más allá de la diversidad de realidades regionales, tiene como parámetros ciertas condiciones estructurales, determinadas iniciativas estatales, así como los procesos autogenerados, es decir, las iniciativas de campesinas y campesinos en el marco de sus organizaciones. En la actualidad atravesamos un momento muy dinámico, no sólo por las transformaciones estructurales, sino también por el avance en el desarrollo de los movimientos que señalábamos inicialmente, que actúan desde hace décadas hacia su interior, y que si bien siempre han demandado respuestas políticas, en la actualidad se han integrado a procesos de disputa y construcción de políticas públicas.

Muchas de esas actividades que han caracterizado las experiencias históricas de organizaciones y movimientos populares rurales han tenido un componente de intento de mejora de las condiciones económicas y productivas, y ese sentido sigue hoy presente. Lo novedoso, podría decirse, es que actualmente están puestas en perspectiva de la construcción de un modo de desarrollo propio y este incluye a las prácticas productivas campesinas orientadas fundamentalmente a la producción de alimentos. Nos referimos a prácticas económicas actuales y proyectadas y a un modo 
de desarrollo que es visto como antagónico a las prácticas empresariales designadas como "el agronegocio". El avance del modelo de los agronegocios es fuertemente criticado. Más allá de los perjuicios ambientales y sobre la salud de los trabajadores rurales y las comunidades afectadas por las actividades productivas, la economía dominante es vista como carente de oportunidades de trabajo y reproducción. No hay trabajo, "y no va a haber trabajo", porque el modelo supone aplicación de tecnología intensiva y monocultivos agrícolas que no requieren cuidados. El modelo de agronegocios, a la par que demanda menos puestos de trabajo ${ }^{7}$, suma brazos disponibles en las pequeñas localidades rurales, donde acaban alojándose los que eran asalariados de haciendas, configurando esas situaciones de pobreza observable en los pueblos y pequeñas ciudades rurales. Las salidas más tradicionales, la proletarización rural o la migración al mundo urbano dejan de ser posibles o bien pierden su atractivo, porque se conoce que no abundan oportunidades laborales y se desconfía del modo en que se está viviendo la cotidianidad urbana: la violencia y el consumo de drogas aparecen como constitutivos del medio urbano en el que a fin de cuentas deberán crecer los hijos y los nietos.

¿Cómo se continúa entonces la vida, e incluso, cómo alcanzar alguna mejora en términos de calidad de vida?, ¿cómo se logra la reproducción de las familias? Como respuesta a estas preguntas emergen las oportunidades de recampesinización, donde la existencia o el desarrollo de organizaciones sociales y movimientos juegan un papel decisivo. Un rol que se asienta en iniciativas orientadas a la mejora de las actividades habituales y al desarrollo de otras, nuevas, que favorecen el arraigo de las familias.

A continuación intentaremos recrear los desafíos construidos por distintas organizaciones con las que hemos trabajado, relativos a la vida económica, en un intento de mostrar un panorama general pero si por eso pretender exhaustividad y diciendo, a riesgo de ser insistente, que se trata de un acercamiento parcial y limitado. Más adelante intentaremos delinear el costado pedagógico de estos desafíos.

a) Dejar de trabajar para otro

Muchas unidades campesinas familiares construyen una estrategia de ingreso combinando distintas iniciativas: la producción para el autoconsumo y para demandas del mercado y la práctica

\footnotetext{
7“También ha sido un factor co-variable de este proceso de recampesinización la reducción en la demanda de mano de obra rural, dado que las poblaciones que no optaron por la migración campo-ciudad, se encontraron con la necesidad de gestar su reproducción al margen de la venta de fuerza de trabajo" (DOMÍNGUEZ, 2011, p. 6)
} 
laboral "extrapredial" que puede ser de uno o varios miembros de la familia: la migración temporal, el trabajo en ocupaciones estables o esporádicas en el campo (peones de estancia, hacheros, entre muchos otros) ocupaciones en ciudades y pueblos cercanos (en la construcción o el trabajo doméstico, por ejemplo) y el trabajo estatal. "Trabajar para otros" suelen decir los campesinos, lo que suele significar algo definitivamente menos valioso que "trabajar para uno mismo". Compartimos algunas significaciones referidas a este modo de trabajo:

\begin{abstract}
"Me he ido a las estancias, dos hermanos míos trabajan en estancias... Si, va a trabajar, va a sacar su sueldo cada quince días, si... pero usted no va a ser joven toda la vida, ¿y a dónde nos metemos? ¿trabajamos para qué?, los de la estancia, tenés 50 o 60 años y te van a decir 'andate'. Yo por lo menos tengo mi casa, mis chivas, llego a una edad y tengo por lo menos donde estar, tengo los animales míos... Yo le dije a mi sobrino, ¿¿usted sabe lo que tiene que hacer acá?, dos o tres meses e irse', porque lo estaban usando, lo mandaban para todos lados... Acá no, acá si tenés que hacer un pozo o un corral, lo hacés, pero a voluntad tuya, no te tienen que andar mandando, y andás tranquilo, si querés ir a la casa de ella, vas... [si quisiera puedo ir] a ver a mi madre... (Antonio MTE- La Comunitaria, Oeste pampeano)

¿Por qué salimos nosotros si estamos defendiendo y por qué vamos a trabajar a un empresario pudiendo hacer cosas aquí?, y no estamos trabajando la tierra [si salimos]... Por ahí hay que hacer cosas para generar trabajo aquí, puestos de trabajo aquí (Omar, MOCASE VC)
\end{abstract}

Este último razonamiento enfatiza el hecho de que trabajar para afuera impide trabajar en los propios territorios y, de ese modo, no se inician (o se interrumpen) actividades que permitirían quedarse y desarrollar una práctica productiva que alcance a las expectativas de bienestar que se sostienen. E incluso superar lo que ofrece el trabajo asalariado en términos de calidad de trabajo. Notoriamente, el trabajo para afuera interrumpe o secundariza el trabajo en el propio predio. Dependiendo del tiempo y la cantidad de personas que se alejan, las actividades se discontinúan en distinta medida. Decíamos antes que además, el esquema actual limita la oferta de trabajo para otros, lo que favorece la afirmación de la vida en el predio, la decisión de quedarse.

A menudo suele enfatizarse otro aspecto de la cuestión que es la preocupación por la posibilidad de inserción económica de los hijos, el riesgo de que ellos sí decidan irse porque la producción familiar genera ingresos muy bajos.

Estos son elementos colaboran en la decisión de afirmarse en la identidad campesina y comenzar a apostar por las producciones propias. Para muchos sujetos y familias esa apuesta ya no se hace en sentido individual o familiar solamente: para muchos campesinos ser parte del movimiento redimensiona su estrategia productiva y la inscribe en una lucha social más amplia. 
Beco da cuenta de una estrategia productiva familiar que se articula a la experiencia más amplia del movimiento, y expresa en sus palabras todo un proceso de elaboración colectiva de criterios acerca de un "modo de producción campesino" en construcción.

[...] yo estoy laburando en la carpintería [del MOCASE VC]. Uno va haciendo... Era productor algodonero ${ }^{8}$, dejé de ser productor algodonero, ahora estoy criando animales, tenemos vacas, vamos aumentando la producción de eso, estamos apostando a la ganadería que es más rentable que la agricultura. Aquí en la zona seca es cuestión de suerte, llueve o no llueve. Si no llueve, bueno, ya está. Y sin embargo los animales, vos tenés agua de un pozo, baldeas y bueno, se mantiene. Nosotros siempre hemos dicho que la producción campesina tiene que ser diversa, varias producciones: gallina, pavo, pato, chancho. [...] (Beco, MOCASE $\mathrm{VC})$

Salirse del mercado, o mejor dicho, de las prácticas dominantes de mercado, diversificar la producción, agregar valor a los productos básicos, practicar el autoconsumo, construir o sumarse unidades económicas integradas a la organización, respetar los procesos naturales, defender las semillas, son buena parte de los aspectos que definen el proyecto social de las campesinas y los campesinos en sus aspectos económicos.

Desde la perspectiva del campesinado, ya no como conjunto de familias campesinas sino como sujeto político que se expresa en un movimiento social, lo productivo se articula intensamente con la lucha por la tierra, con la lucha por políticas que acompañen el desarrollo campesino y por recursos públicos y, a mayor plazo, con la lucha por otro horizonte de organización de la economía. Se afirma la relación entre la lucha del movimiento y la producción:

[...] seguramente la mejor forma de defender el territorio es produciendo. Porque si vos no tenés opciones de trabajo en el territorio te tenés que ir, seguramente a buscarlo a otra zona. [...] Y a partir de lo productivo viene todo lo demás, ¿no? Salud, educación, montones de cosas... La gente tiene que trabajar, tiene que subsistir, mantenerse [...] (Oscar, MOCASE $\mathrm{VC})$

El Estado provincial quiere que estemos salidos de la huerta para que no haya desarrollo autónomo. La decisión política tiene que ser proyectarse en ese regreso a la huerta aprovechando también el territorio (Ariel Epulef, Comunidad Mapuche Curruhuinca, MTE Rural Neuquén)

\footnotetext{
${ }^{8}$ De acuerdo con Domínguez, la crisis de la producción algodonera en el Chaco y Formosa, provincias que integran el Gran Chaco junto a Santiago del Estero, orienta a los campesinos en el sentido de la producción autónoma, especialmente ganadera (DOMÍNGUEZ, 2011)
} 
El acierto en las iniciativas de producción campesina se torna crucial para mostrar que se pueden hacer las cosas de otro modo. Es crucial, en términos políticos, lograr que las actividades productivas, especialmente las iniciadas por familias jóvenes, no fracasen, se potencien y generen entusiasmo en otros sujetos.

\section{b) Ensayar alternativas}

En ese sentido, se realizan muy variadas acciones que orientan a mejorar y a viabilizar prácticas que se vienen ejerciendo, recuperar algunas otras que se dejaron de ejercer así como impulsar otras nuevas. Destacaremos algunas de las iniciativas sobre las que tuvimos oportunidad de indagar.

* Entre las primeras, las relacionadas a mejorar prácticas actuales, y a modo de ejemplo, se buscan soluciones conjuntas relativas a las prácticas ganaderas que ya las familias están desarrollando. Aquí podemos hacer entrar experiencias muy diversas; como el caso de administrar colectivamente vacunas. En ese caso se abaratan los costos al comprar en cantidad, y se procura que algún integrante de la organización tenga la posibilidad de certificar la vacunación, que es condición sanitaria para la venta del ganado. La compra colectiva de forrajes es otro ejemplo de una acción orientada a mejorar las condiciones de producción a través de una acción colectiva, en algunos casos poniendo en juego recursos colectivos para el transporte, frecuentemente utilizando contactos con productores aliados de otras localidades.

* El reemplazo de insumos comprados al mercado por otros producidos en el marco de las organizaciones, ha sido una línea de actividad muy desarrollada especialmente en las actividades de las familias más articuladas a procesos mercantiles. Suele ser pensado en términos de abaratamiento de los costos, pero también se relaciona con el control de los mismos, escapando de las especulaciones de mercado, y en algunos casos, con control de la calidad. El desarrollo de insumos "no convencionales"9 como plantines propios, humus, biofertilizantes, va más allá de la baja de costos, aporta a propuestas de producción más saludables para las y los trabajadores y para quienes consumen sus productos, cuestión que retomaremos más adelante.

\footnotetext{
${ }^{9}$ Se utiliza coloquialmente el término "convencional" para mencionar las formas de producción dominante, apoyada en insumos químicos, en contraposición, por ejemplo, a las prácticas agroecológicas.
} 
* el desarrollo de sistemas de préstamos bajo distintas modalidades, sistemas rotatorios para el desarrollo de inversiones, sistema de préstamos de urgencia (por ejemplo, un banco de nylon para la cobertura de invernáculos rotos por temporal), sistemas de adquisición de maquinaria para uso rotatorio, son mecanismos recurrentes.

* Un conjunto de iniciativas se dirigen al desarrollo de infraestructura de uso colectivo, como es el caso del de pozos de agua comunitarios con molinos de viento, para la actividad ganadera, en sitios sin acceso a la electricidad de red. En este último caso se evitan los intensos trabajos dedicados a la obtención y trasporte del agua en épocas de sequía. Redes de agua construidas colectivamente son frecuentes en muchos puntos del país, allí donde la política pública no lo impulsa, son los propios movimientos los que disputan recursos y a menudo construyen esas instalaciones. Los galpones de acopio de uso colectivo son frecuentes también en diversas organizaciones. También es habitual la adquisición de medios de producción que se usan de manera compartida: tractores, vehículos de carga, maquinaria, entre otros.

Por otro lado, se generaron muy variadas experiencias laborales colectivas, entre las que son frecuentes las fábricas donde se agrega valor a la producción, elaborando dulces, conservas, harinas, quesos, muebles, y muchas otras actividades que se realizan con diverso grado de tecnificación, aunque en general con niveles de tecnificación intermedio.

La carpintería, instalada en Quimilí por el MOCASE VC, representa una iniciativa de aprovechamiento de las maderas duras del bosque en un uso menos dañino que el tradicional: la producción de carbón vegetal. En muchos casos se inician actividades nuevas, no tradicionales entre las y los campesinos, como por ejemplo, en distintas experiencias, la producción de miel. El contacto con mercados urbanos a través de las organizaciones y sus alianzas favorece esos desarrollos. Estas iniciativas no son orientadas exclusivamente en el sentido de la mejora o estabilización de los ingresos. En estos casos, comienzan a jugarse valores definidos colectivamente y articulados al proyecto social: la mejora en las condiciones laborales (notoriamente definitorias en iniciativas como abandonar la producción de carbón vegetal o el uso de pesticidas), las producciones con cuidado del ambiente, las que recuperan o fortalecen prácticas alimenticias o culturales de las comunidades o regiones en que se insertan, las que permiten priorizar el trabajo de jóvenes, o bien de mujeres, contrarrestando procesos que los y las expulsan o subalternizan. 
Una iniciativa que podría ser un buen ejemplo de los esfuerzos colectivos en esa dirección el desarrollo de una fábrica de fécula de mandioca (yuca), realizado por COTRUM, en el norte de Misiones. Se trata de un proceso de agregado de valor de un producto que encaja en la propuesta productiva campesina. Por una parte, permite reemplazar el tabaco, producción a partir de la cual muchas familias logran ingresos monetarios. La producción de tabaco se cobra una vez al año, al entregar la cosecha, y resulta un ingreso significativo, aunque difícilmente reconozca la cantidad de trabajo puesto a lo largo del año. Se realiza de manera integrada a empresas capitalistas, que proveen los plantines, insumos (alta y variada cantidad de agroquímicos) y pagan el trabajo familiar al recibir la cosecha. La producción de mandioca, al contrario, es controlada por las y los campesinos, no requiere insumos más allá de los disponibles en el predio, sirve de alimento a las personas y al ganado. La elaboración de fécula se orienta a un mercado fundamentalmente regional, aunque migrantes de la región también son consumidores habituales de subproductos muy arraigados en las prácticas alimentarias, como el mbeyú y la chipa. La fábrica, por otra parte, pone en juego tecnologías adaptadas especialmente a la escala productiva que alcanzan las familias, de modo de mantener productividad sin excederse en costos elevados.

Unidades de comercialización locales, como carnicerías y almacenes han comenzado a desarrollarse en distintos puntos del país. A través de ellas se busca llevar al mercado, por medios propios, la producción de las familias, al mismo tiempo que se desarrolla un espacio de interacción cotidiana con gentes de los pueblos rurales.

Existen además otras actividades de comercialización que se realizan desde los movimientos: la participación en eventos como ferias o espacios públicos, la instalación de puestos en ciertas concentraciones públicas en zonas urbanas ${ }^{10}$.

En muchos casos los momentos de venta son considerados momentos de expresión pública, pero incluso en ciertas oportunidades son asociados a movilizaciones y protestas. En las grandes

\footnotetext{
10 "Esa fue la modalidad que nosotros le encontramos para dar visibilidad frente al vecino de a pie y frente a las autoridades y también frente al movimiento. Nosotros siempre tenemos un debate sobre cómo salir a la calle. Si lo hacemos de manera convencional, ir frente al ANSES y decir "fuera FMI", con los bombos y las banderas, o buscando otra forma de convocar a nuestros propios compañeros y que les permitiera reconocerse en todo lo que están produciendo, donde ellos también pudieran ser valorados, reconocidos por otros socialmente.” (Carlos, La Comunitaria-MTE, Oeste Pampeano)
} 
ciudades vienen siendo frecuentes los "feriazos" como formas de lucha donde las los productores huerteros venden a precios muy bajos la producción, mostrando lo mal pagas que resultan y el carácter especulativos de los precios minoristas con los que se encuentran las familias urbanas. Este tipo de medidas han al mismo tiempo generan la adhesión de multitudes atraídas por los precios bajos, lo que fortalece la movilización.

Una importante porción de las producciones colectivas se canalizan a partir de la articulación con organizaciones urbanas dedicadas a la comercialización (o bien a prácticas de consumo conciente), asociadas al consumo de productos agroecológicos o bien de productos de origen autogestivo.

A través de los procesos de lucha y negociación distintas organizaciones han logrado gestionar espacios de comercialización en mercados públicos concentradores, con ventas tanto mayoristas como de tipo minorista.

El trabajo en las carnicerías, en la carpintería y en los procesos de agregado de valor, sin ser del todo ajenas, no son estrictamente tareas habituales del campesinado. Lo mismo ocurre con otro tipo de acciones donde se conforman equipos de trabajo, relacionados fundamentalmente al desarrollo de infraestructura, como la construcción de aljibes y pozos, redes de agua, el montaje de galpones, o la construcción de edificios de la organización. Generalmente para estas iniciativas se gestionan recursos que permiten pagar la fuerza de trabajo que aportan participantes de la organización y que de ese modo, en algunos casos, van construyendo un saber laboral específico.

Para el desarrollo de estas acciones entran en juego procesos de capacitación e iniciativas de obtención de recursos, que suelen designarse coloquialmente como "los proyectos" y que se solicitan a entidades de la comunidad internacional que suelen aportar a experiencias relacionadas al campesinado, a la producción de alimentos sanos, a la lucha contra la pobreza y/o a la defensa del ambiente. En los últimos años se ha incrementado la búsqueda de recursos públicos, especialmente de nivel nacional. Esta segunda línea de acción politiza fuertemente los procesos y orienta en el sentido de poner en agenda el lugar del campesinado en la economía nacional.

A la par de esa procura de recursos externos, también podemos notar que algunas de esas iniciativas trabajan proponiendo la colectivización de recursos existentes o la generación de recursos propios.

c) Afirmarse como campesinos 
Las prácticas productivas se inscriben en un proceso que suele designarse, desde la mirada académica, como recampesinización (DOMÍNGUEZ, 2012; PAZ; JARA, 2006). Básicamente, el razonamiento que atraviesa esa mirada sobre el tema supone que cuando las condiciones de producción y reproducción son inapropiadas y existen posibilidades de intensificar la relación con los mercados se produce un proceso de abandono de la posición campesina (la descampesinización ${ }^{11}$ ), para pasar a convertirse en jornaleros o asalariados rurales o bien, en otras condiciones, capitalizarse y tomar la forma de productores con capacidad de explotación de mano de obra externa a la familia.

La recampesinización consiste en un proceso de vuelta a la posición campesina -en virtud de que han desaparecido los estímulos y presiones que provocaron la descampesinización-, caracterizada por el trabajo en una tierra propia o en uso, la utilización de mano de obra familiar (generalmente no pagada en dinero), producción para autoconsumo articulada con algunas producciones dirigidas al mercado y escasa o nula capacidad de capitalización.

Por una parte, debemos destacar lo que ya hemos señalado al considerar los procesos de lectura de la realidad histórica reciente que hacen los campesinos. El proceso de "descampesinización" es visto desde una perspectiva crítica por el modo en que se naturalizaron ciertas condiciones de explotación, de consumo, en fin, de formas de vida a partir de valores que, con el proceso de organizarse y construir lecturas colectivas de la realidad, comienzan a ser cuestionados más sistemáticamente. Pero no es solamente este cambio de lectura o el fortalecimiento de las críticas dispersas que algunos sujetos venían ejerciendo, lo que emerge del proceso de estar organizado. Son por lo menos otras dos cosas las que se mencionan.

Por una parte, la capacidad política de los sujetos una vez organizados permite alcanzar determinados objetivos relacionados al acceso a servicios e infraestructura que antes se intuían posibles pero que no era realdades efectivas. Organizados los campesinos consiguen escuelas, para poner un ejemplo del terreno del derecho social, que se efectiviza a partir de la existencia de algún tipo de organización popular.

\footnotetext{
${ }^{11}$ En muchos países. Los pequeños propietarios o arrendatarios se ven sometidos a una creciente presión para abandonar por completo el sector agrícola. Detrás de este proceso de descampesinización se encuentran fuerzas de mercado y políticas que afectan la tenencia de la tierra, los alquileres, los precios, el crédito, los insumos y la inversión pública en infraestructura física y social (PÉREZ et al., 2007).
} 
Pero además, organizados se pueden realizar logros que las unidades campesinas domésticas, por sí solas, no estaban pudiendo realizar. Las prácticas de intercambio recíproco y los proyectos comunes, que, como vimos, eran vistos como parte de las tradiciones campesinas, muchas de las cuales son señaladas como herencias del pasado indígena, y se mencionan con añoranza e interrumpidas por los efectos privatizadores que resultan del avance de las relaciones capitalistas y de la acción del estado durante el siglo XX, son recuperables a partir de la existencia de una organización que genera la posibilidad de recrear la comunidad.

Por otro lado, la subsistencia campesina, su capacidad productiva y reproductiva se convierte ya no sólo en un problema doméstico sino en un elemento político que se presenta como emergente y que se propone como contrincante en la disputa por otro modelo de desarrollo. En ese marco se despliegan dos procesos que son complementarios pero se pueden describir por separado.

Uno, la ampliación de la capacidad productiva por la vía de iniciativas organizadas: obtención de recursos, prácticas comunes, planificaciones compartidas, tal como hemos descripto más arriba. Esta iniciativa que procura mejorar y ampliar la producción excede a la unidad doméstica al involucrarla en iniciativas comunitarias y establece sus posibilidades de éxito económico en la agregación de trabajos extrafamiliares, articulados a nivel local, regional e incluso complementarios en relación a otras organizaciones del mundo urbano. La acción económica tiene más posibilidades de éxito en la medida que se realiza en la interacción colectiva y se liga a un conjunto amplio de relaciones sociales autónomas. Esa interacción no implica colectivización ni cooperativización de todos los procesos, sino la articulación (que toma variadas formas) de instancias de trabajo individual, familiar y colectivo.

Dos, el proceso político y cultural que tiene una dimensión económico-productiva decisiva, que involucra tanto la reapropiación de la tradición campesina indígena (con los valores selectivamente activados: trabajo no enajenado, "para uno y no para otro", autodeterminación de las comunidades, respeto de la biodiversidad, producción de alimentos sanos, etc.) como la puesta en discusión de las pautas de trabajo, consumo, producción y la relación con la naturaleza propias del capitalismo actual.

Se trata de iniciativas que otros análisis, como el realizado por Diego Domínguez, sitúan como parte de procesos más generales: 
[...] entendemos que la recampesinización, pero más precisamente la actualidad de la cuestión campesina en Argentina, puede comprenderse en tanto campo de experimentación socioeconómico y político, cuya significancia reside en el contrapunto con la agricultura industrial, pero también en tanto afirmación de nuevos vínculos de cooperación productiva, de reciprocidad con la naturaleza, y de reorganización ética de la dicotomía campo-ciudad. (DOMÍNGUEZ, 2011, p. 10)

El analista que citamos es enfático con respecto a la relación entre los procesos políticos, sociales y económicos que se despliegan alrededor de las prácticas que recrean el campesinado. Las iniciativas se inscriben y nutren en un imaginario alternativo al dominante, que comienza a ofrecer pautas de lectura de la realidad y de afirmación de intencionalidades propias:

Experiencias que operan en escalas geográficas diversas y con diversos grados de consolidación y precariedad. Experiencias que -insistimos- dan cuenta y son indicadores de la emergencia de un sujeto político, anclado en las familias y comunidades de productores directos, que está demostrando intención y capacidad (potencia) de territorializarse, desproletarizarse, descolonizarse, recomunalizarse, cooperativizarse. (DOMÍNGUEZ, 2011, p. 10).

La clave de lectura de estos procesos radica en la imposibilidad de pensarlos como autónomamente económicos: son el resultado de procesos de afirmación que contienen una dimensión de sujeto político puesta en primer plano; además de económicos, son procesos culturales, identitarios y políticos, son, en sentido estricto, procesos sociales.

d) La economía campesina, el proyecto social y la factualización de alternativas

En su caracterización de los movimientos sociales latinoamericanos, Raúl Tapia intenta considerar conceptualmente la capacidad de estos para materializar alternativas sociales o en otros términos, para mostrar la posibilidad de otra realidad.

Uno de los rasgos del desarrollo de un movimiento social es que su accionar tiende a incluir ya no sólo la protesta o la demanda, sino también la factualización de las formas alternativas de apropiación, gestión, organización y dirección de recursos y procesos sociales y políticos. La factualización de alternativas es un arma de lucha dirigida a convencer al estado y a la sociedad civil de la posibilidad de hacer, organizar, dirigir y vivir las cosas de otro modo; la capacidad ya desarrollada por el movimiento para pasar de la crítica a la reorganización de las cosas. Un movimiento social ha madurado cuando ha desarrollado la capacidad de proyectar formas alternativas de organización y dirección, sobre todo cuando ha desarrollado la capacidad de movilizar sus fuerzas para cristalizar el proyecto. La factualización crea las condiciones para la consolidación, el arraigo y la cristalización de un movimiento. Un 
movimiento que no pasa a la factualización de sus ideas se convierte en o es simplemente opinión crítica en la esfera de lo público. (TAPIA, 2008, p. 60; 61)

Este recorte de la realidad que realiza Tapia para prestar atención a la capacidad de propuesta social de los movimientos no suele estar presente en las lecturas teóricas acerca de los mismos. Sin embargo, sí es llamativo como en la práctica de los mismos esta dimensión es sumamente valorada. La construcción de alternativas productivas se orienta por objetivos que si bien son complementarios pueden ponerse en distintas escalas: se busca que fortalezcan las posiciones campesinas en los territorios, que permitan la reproducción de las familias, que se mejore la calidad de vida y el ingreso familiar, que se evite la migración a la ciudad de los más jóvenes, que se logre impactar sobre los mercados locales y que se produzcan alimentos de manera masiva, reivindicando de ese modo el aporte campesino a la alimentación de la población.

A partir de la mera reproducción de las familias en condiciones de respeto a la biodiversidad, la práctica social-productiva del campesinado ya puede presentarse como una alternativa viable de reproducción de la vida que es además de un impacto ambiental positivo. En tal sentido se expresa la consigna de la Vía Campesina: "la agricultura campesina enfría el planeta".

Para proyectarse como alternativa superadora de la realidad actual y con capacidad de lograr la adhesión de otros sectores sociales, necesita potenciarse: no puede ser alternativa una economía que expulsa su mano de obra joven, tiene que poder retenerla. Su carácter de alternativo también puede discutirse si requiere de períodos de trabajo bajo relaciones salariales de uno o varios miembros de la familia para garantizar la reproducción. No puede además presentarse como alternativa si no disputa un papel más significativo en la producción de alimentos para el mercado interno. Las posibilidades de potenciación de la alternativa campesina no se agotan en la disputa por la reorientación de las políticas públicas - en general, francamente adversas-, y de la asignación de recursos; se observa además la posibilidad de avanzar a partir de procesos de autoorganización e innovaciones productivas y de organización del trabajo que se van construyendo. El desafío de potenciar la producción se presenta como un elemento estratégico para la disputa política y para llamar la atención sobre el proyecto político propio especialmente para sectores que son ajenos a la realidad rural.

Por supuesto, esas propuestas se desarrollan en un trasfondo económico que es adverso al campesinado y que esbozamos al inicio del texto. No vamos a detenernos en este punto, pero debemos señalar que el proceso de disputa de las heterogéneas organizaciones campesinas del país condujo a 
procesos de articulación y de construcción de plataformas, como es el caso del Foro Social Agrario ${ }^{12}$ y sus propuestas y llevó a ubicar a referentes campesinos en el aparato de estado a partir de la alianza con el Frente de Todos ${ }^{13}$.

Si se lo expresa en términos económicos, el proyecto social que se desprende de las iniciativas de los movimientos populares rurales se está factualizando en el presente. A la vez, la lucha política se enuncia en el sentido de políticas económicas que no sean adversas -como las que hoy favorecen al capital concentrado y a las trasnacionales- y por la "recuperación" de la tierra expropiada por el latifundio para ponerla en manos de quienes quieran trabajarlas, y por tanto, ampliado hacia más sujetos que hoy no viven en el mundo rural. Lo que se impulsa actualmente puede imaginarse complejizado a partir de la diversificación de prácticas productivas locales, no sólo agropecuarias, y de la incorporación de más y variadas tecnologías "apropiadas" y desarrollo de infraestructura acorde al modelo de desarrollo sostenido. Todo esto sobre un trasfondo de autodeterminación que tampoco representa una novedad completa, en la medida que hoy las comunidades ejercen niveles de autogobierno significativos.

\section{LA FORMACIÓN EN TORNO A LO PRODUCTIVO}

Este horizonte estratégico presenta desafíos relativos a las necesidades de conocer y de formarse para abordarlo. Se suelen desplegar procesos de capacitación, existentes desde momentos muy tempranos de cada experiencia: muchos y variados cursos o espacios de intercambio acerca de temáticas que se priorizan colectivamente, donde incluso la gente se desplaza de un sitio a otro para conocer cómo se hace en otras situaciones.

Numerosas organizaciones han desarrollado procesos educativos propios articulados con el horizonte estratégico del modo de producción campesino. Procesos de intercambio y formación

\footnotetext{
${ }^{12}$ El Foro Social Agrario tuvo su jornada inicial los días 7 y 8 de mayo de 2019. Permitió la confluencia del heterogéneo conjunto de movimientos y organizaciones rurales populares. Constituyó un momento de síntesis de las ideas, experiencias y propuestas construidas por estas. Más información en http://foroagrario.org/

${ }^{13}$ Con el triunfo del Frente de Todos asume la presidencia Alberto Fernández, inscribiéndose en la tendencia de los gobiernos progresistas latinoamericanos tras cuatro años de gobierno de Mauricio Macri, que interrumpieron el ciclo progresista con propuestas neoliberales radicales y con apoyo del FMI y la Casa Blanca. El ascenso de Macri se dio a la par de la estigmatización de las luchas populares desde el gobierno y desde los medios de comunicación concentrados. Más allá del carácter contradictorio del ciclo progresista (BRINGEL; FALERO, 2016), el Gobierno de Fernández incluye en su gabinete a numerosos militantes de origen popular, que participan orgánicamente.
} 
relativos a la producción, cursos de capacitación de diverso tipo, asistencia en los predios de técnicos formados en universidades o en los propios movimientos. Un aspecto destacable es el desarrollo de las escuelas de agroecología de distintos movimientos, de la que es pionera la Escuela del MOCASE VC, en la localidad de Quimilí (BURGOS, 2013; GUELMAN 2015 a y b) y la Universidad Campesina, del mismo movimiento. Se suman en distintos puntos del país disputas por la presencia de escuelas, por los recursos para mantenerlas y además por la participación en ellas de las organizaciones del mundo indígena y campesino, para que acompañen y para que antagonicen con las comunidades y movimientos campesinos. En parte a eso se refería Teresa Tripelaf cuando decía "uno tiene la esperanza que los chicos nuestros sean ellos mismos el educador".

De todos modos, la dimensión formativa está lejos de agotarse en los aspectos de capacitación técnica. En buena medida, la iniciativa pedagógica circula por otro camino: relacionada a los aspectos ideológicos y de construcción sobre el proyecto y que supone proponer a los sujetos que se posicionen de otro modo frente a la actividad productiva, no subsumidos al capital sino realizando su propia producción y en vínculo con su comunidad; pensarse con capacidad de desarrollar una iniciativa de producción articulada a la vida comunitaria distante de las relaciones de sujeción dominantes.

En buena medida, la iniciativa formativa se orienta a trabajar sobre el sentido de posibilidad, de que es necesario y posible desarrollar un camino productivo campesino con mayor autonomía respecto de las relaciones económicas dominantes. Y eso supone un desafío:

[...] compañeros que hoy siguen apostando por la producción de carbón porque no encuentran... "No encuentran", no. No ven que hay otra producción que puede redituar económicamente tanto o más que esa y que no es tan destructiva del bosque. (María de los Ángeles, MOCASE VC)

En su apreciación de la Escuela de Agroecología, Guelman (2015) destaca la presencia de una formación técnica entendida en sentido amplio, incluyendo la comprensión de los procesos más generales en que la actividad se inscribe y apropiándose de recursos para la gestión integral de los procesos productivos:

Se trata entonces de formación para un nuevo concepto de trabajo, de formación como apropiación de recursos para la participación en la gestión de la producción, de formación para la comprensión crítica de los contextos en los que estas nuevas formas de concebir el 
trabajo deben operar, y de las contradicciones que estos contextos plantean y que supone un nuevo tipo de sujeto y de trabajador. [...] En la escuela se trabaja desde una concepción amplia del "trabajo", como parte de una economía que se aleja de los parámetros del capital, que comparte la propiedad sobre los medios de producción y que no busca acumular. (GUELMAN, 2015, p. 91; 216)

La intencionalidad formativa de los movimientos se relaciona con poder dirigir la mirada acerca de lo posible y lo imposible en torno a lo productivo; dicho de otro modo, significa invitar a correrse de las respuestas naturalizadas acerca de las salidas económicas, y en tal sentido, acercarse a la posibilidad de apostar por otras prácticas que involucran a la familia y a la comunidad.

Por otra parte, implica hacerse de saberes relacionados a la producción en sus aspectos técnicos y de gestión. Y en tal sentido, apropiarse de los saberes técnicos y sociales más amplios existentes en las comunidades e incorporar otros, cuyo origen social es más diverso, incluyendo la formación científico-técnica de matriz académica, las experiencias desarrolladas en otros movimientos y organizaciones sociales, los debates en torno a la soberanía alimentaria, la autogestión del trabajo, así como profundizar en la crítica del capitalismo y del modo en que se expresa en el mundo rural en la actualidad.

\section{LOS OTROS SABERES NECESARIOS}

Cuando los movimientos despliegan iniciativas de afirmación del modo de vida campesino, cuando, en términos de Tapia, "factualizan alternativas", construyen ciertas realidades que representan desafíos de conocimiento, en tanto lo nuevo, lo que está siendo construido, pone a los sujetos frente a preguntas que no siempre son factibles de responderse con la experiencia y saberes desarrollados hasta el momento, incluyendo aquellos recuperados en los procesos de afirmación de las identidades campesinas e indígenas.

Este tipo de iniciativas, en muchas oportunidades, hacen entrar en juego a sujetos con experiencias diferentes a las de las comunidades, que aportan su formación específica, destacadamente, quienes cumplen un rol especializado, de carácter técnico o profesional. No se trata de un sujeto ausente en las experiencias de organizaciones y movimientos; al contrario, en casi todas participan y muchas veces motorizan procesos de organización desde su inicio. Pero al momento de 
desplegar iniciativas de pensamiento de las nuevas realidades en construcción, su aporte suele ser específico en lo que refiere a los saberes que pueden aportar a la actividad de las comunidades. De ningún modo esto significa que las comunidades campesinas no sean quienes investiguen esas nuevas realidades. De hecho, esa actividad es parte de la praxis cotidiana del campesinado (DÍAZ TEPEPA et al., 2006), pero el diálogo con actores con otras experiencias y saberes fortalece esa praxis. Esa articulación suele resolverse en las organizaciones populares a partir de la construcción de un diálogo permanente, apoyado en la praxis común que tienen esos sujetos de distintas procedencias, que en muchos casos se despliega por largos períodos. Esa praxis compartida, si bien facilita el diálogo de saberes, no resuelve de manera directa la complejidad de ese vínculo que es tanto social y cultural, como epistémico.

Este hecho representa desafíos intelectuales y políticos en múltiples dimensiones. Pone a los saberes profesionales, a menudo especializados, a jugar alrededor de problemas complejos, en creación, inéditos, en torno a los cuales dialogan distintos sujetos que asumen protagonismo. Se trata de sujetos con saberes; saberes conformados de manera distinta a los saberes académicos, validados de otras maneras, articulados a esquemas de valores que muchas veces no se alcanzan a reconocer, saberes situados, saberes anclados en memorias históricas. Por otra parte, se trata de sujetos diversos, que se formulan preguntas en el marco de una praxis colectiva y que están lejos de confiar ciega o plenamente en las respuestas generadas en el campo académico o técnico profesional. Se trata de sujetos que protagonizan procesos, que deben construir acuerdos con otros antes de hacer, sujetos cuya vida se articula con eso que factualizan. Estas características de esos sujetos y de sus saberes están lejos de ser parte de los temas que se abordan el la formación técnica y profesional.

Esos sujetos formados en una matriz epistémica, necesitan (necesitamos) revisar con profundidad los determinantes de los modos de ver, pensar e investigar. Las construcción de problemas de investigación a menudo en respuesta a políticas hegemónicas, cuando no a la preocupación individual de cada investigador o investigadora, que suele determinar qué es lo central y qué no, en cada realidad que observa, el carácter individualizante y competitivo de la tarea investigativa, la tendencia a construir discursos que expliquen, pero además proclives a indicar y prescribir, omitiendo que cualquier prescripción contiene un horizonte y un sentido que puede ser debatido colectivamente, la tendencia a validar lo que se sabe y lo que se investiga con parámetros de 
su propia comunidad, sin dar cuenta a otros y a otras; en fin, un conjunto de características que hacen a las formas de hacer y de conocer de un tipo particular de sujetos.

Estas preocupaciones vienen siendo puestas en debate en torno a la noción de "diálogo de saberes" que la autora que citamos a continuación (MICHI, 2019 a y b) problematiza desde su preocupación por las formas de construcción de conocimiento en los movimientos populares:

El auténtico diálogo de saberes pone en cuestión la raíz colonizadora de la llamada ciencia, lo que implica considerar válidos esos saberes populares y también reconocer su carácter dinámico no anquilosado y también provisional como todo conocimiento. En este sentido nos parece fundamental un verdadero diálogo que acepte, valore $\mathrm{y}$, sobre todo, no anule las capacidades de conocer, ser considerado más proceso que producto, en términos freireanos "hacerse verbo" (MICHI, 2019b, 82)

\section{ALGUNAS REFLEXIONES PEDAGÓGICAS A MODO DE CONCLUSIONES}

Lo que hemos descripto hasta aquí puede recuperarse en clave de algunos puntos de debate pedagógico que emergen de pensar los desafíos de conocimiento cuando pensamos en sujetos colectivos que luchan, resisten y construyen realidades.

Nos hemos detenido en dos intencionalidades políticas y sus respectivas necesidades de producción de conocimiento. Este hecho supone ya un punto de partida pedagógico, que recupera aquella afirmación de que "la educación es política" y que la política siempre supone una cierta actividad pedagógica, afirmaciones que tanto Paulo Freire como Antonio Gramsci desarrollaron con profundidad. Ambos intelectuales miraban con particular detenimiento los procesos de conocimiento y subjetividad de quienes estaban inmersos en procesos de lucha social y proponían diálogos que se nutrieran de la vitalidad de tales experiencias, de las curiosidades que se despiertan cuando se inicia un proceso de lucha y de organización, y muy enfáticamente, cuando se está construyendo algo nuevo.

Existe una afirmación central en Educación Popular: los saberes y subjetividades populares deben ser punto de partida de los procesos de reflexión que se pretenden democratizadores; en ese sentido, partir, respetar y construir desde el saber popular ha sido una constante en la propuesta pedagógica de la EP (DI MATTEO, 2019). Partir de esos saberes significa reconocer que los sujetos vienen actuando en el mundo, son por tanto portadores de experiencia y de saber, cuestión que choca de lleno con la matriz pedagógica eurocéntrica, iluminista, partidaria de una jerarquización de saberes. 
Negar el saber popular es considerado, en la tradición de la EP, como acción idéntica a negar al sujeto y su subjetividad (FREIRE, 2008; 2011).

Al mismo tiempo, construir nuevo saber sin partir de la experiencia popular supone un desarraigo de esos saberes y de esos sujetos, cuyos efectos políticos son adversos a las posibilidades de autonomía social, es decir, de cualquier proyecto sustancialmente democratizador. No es concebible una práctica educativa coherente con un horizonte democratizador, anclado en el protagonismo de las clases populares ${ }^{14}$, que no tenga como punto de partida la lectura popular del mundo.

\begin{abstract}
No hay otro camino sino partir de la realidad en la cual la clase trabajadora se encuentra. Partir del punto de vista de su percepción del mundo, de su historia, de su propio papel en la historia, partir de lo que sabe para poder saber mejor y no partir de lo que sabemos o pensamos que sabemos. Si el punto de partida está en nosotros los llamados intelectuales, no hay otro camino sino el del autoritarismo (FREIRE EN FREIRE; GADOTTI; GUIMARAES, 1987, p. 126; 127)
\end{abstract}

Por otra parte, esa relación entre lo político y lo pedagógico puede leerse también en como una relación entre acción y pensamiento. Quienes provenimos del campo de la educación, pedagogas y pedagogos, profesores y profesoras, solemos pensar los procesos formativos como momentos específicos, separados de la práctica social, organizados en torno a temas cuya relevancia fue establecida en otra parte y por otras personas. Los movimientos populares, y muy específicamente los que se despliegan en el medio rural, suelen afirmar que es la práctica la que enseña, la que forma y construye subjetividades y saberes, la que problematiza, inquieta, formula preguntas.

En otros trabajos hemos intentado describir las diversas prácticas que tiene efectos formativos aun a pesar de que no sean organizadas con esa intencionalidad, o no sea esa la intencionalidad prioritaria (MICHI et al., 2012; 2019). Muchos movimientos, especialmente los que han desarrollado un mayor recorrido piensan la experiencia de sus integrantes de manera pedagógica, o al menos intentan hacerlo, preguntándose por qué efectos formativos tiene hacer las cosas de una manera o de otra. En ese sentido, resulta interesante relativizar esa exclusividad que damos a los momentos de

\footnotetext{
14 Estamos hablando de procesos de transformación de la realidad en que los sujetos del mundo popular no son vistos como beneficiarios o destinatarios de las políticas democráticas sino como protagonistas de la construcción de la sociedad en su conjunto.
} 
intercambio verbal, de diálogo presencial, de puesta en juego de saberes codificados, para pensar las dimensiones pedagógicas de la acción.

Por último, resulta un desafío fuerte abordar los problemas de la interculturalidad, asumir aquel horizonte que trazara Carlos Lenkersdorf $(2005 ; 2008)$ de "aprender a escuchar", que afirma que cada experiencia cultural es otra respecto de la propia, y por tanto, se hace necesario dedicar un tiempo a comprender antes apresurarse a conceptualizar, explicar o prescribir, un tiempo para objetivar nuestros propios prejuicios, nuestra propia formación que nos ha enseñado, profundamente, una lectura peyorativa del campesinado y el mundo indígena, y por otra parte, también un tiempo que es oportunidad para preguntarse por uno mismo y por sus certezas.

Tras la violencia ejercida en la historia, y hasta hoy mismo, afortunadamente las prácticas campesinas e indígenas resisten (o re-existen, como dijera Porto Goncalves) y la apertura a sus formas de ver, de sentir y de interrelacionarse nos aportan muchos elementos para ensayar alternativas que superen este estado de cosas, doloroso estado de cosas, que necesitamos revertir.

\section{REFERENCIAS}

BARBETTA, Pablo. En los Bordes de lo jurídico. Conflictos por la tenencia legal de la tierra en Santiago del Estero, 2012. [mimeo]

BARTOLOMÉ, Miguel (2003). Los pobladores del "Desierto" genocidio, etnocidio y etnogénesis en la Argentina. Cuadernos De antropología Social, n. 17, pp. 163-189, 2003.

https://doi.org/10.34096/cas.i17.4604

BRINGEL, Breno; FALERO, Alfredo. Movimientos sociales, gobiernos progresistas y estado en América Latina. Cuadernos CRH, Salvador, v. 29, n. SPE 03, p. 27-45, 2016.

CALDART, Roseli. Pedagogia do Movimento Sem-Terra. Escola é mais do que escola. PetrópolisRJ: Editora Vozes, 2000.

CASTORIADIS, Cornelius. El Mundo fragmentado. Montevideo: Editorial Nordan Comunidad, 1990.

CASTORIADIS, Cornelius. La institución imaginaria de la sociedad. Vol. 1 y 2. Buenos Aires: Tusquets editores, 1999.

DI MATTEO, Álvaro Javier. Una propuesta para debate sobre el conocimiento popular y su lugar en las prácticas de educación popular. 2019. [Texto en proceso de edición] 
DÍAZ TEPEPA, María Guadalupe; ORTÍZ BAEZ, Pedro; RAMÍREZ, Ismael Nuñez. Interculturalidad, saberes campesinos y educación. Revista Mexicana de Investigación Educativa, v. 11, n. 28, enero-marzo, pp. 333-337, 2006.

FREIRE, Paulo. Pedagogía del oprimido. Buenos Aires: Siglo XXI, 2008.

FREIRE, Paulo. Cartas a Guinea-Bissau. Apuntes de una experiencia pedagógica en proceso. México: Siglo XXI, 2011. Freire, Paulo, Gadotti, Moacir y Sergio Guimaraes (1987 [1985]) Pedagogía diálogo y conflicto, ediciones 5, Buenos Aires

GRAS, Carla; CÁCERES, Diego. "El acaparamiento de tierras como proceso dinámico. Las estrategias de los actores en contextos de estancamiento económico". Población \& Sociedad, v. 2, n. 24, 2017. [en prensa]

GROSSO, José Luis. Indios muertos, negros invisibles. La identidad "santiagueña" en Argentina, 2014. Tomado de internet el 23 de octubre de 2014 en http://www.naya.org.ar/tesis/Jose_Luis_Grosso/jose_luis_grosso_index.htm

LENKERSDORF, Carlos. Filosofar en clave tojolabal. México: Porrúa, 2005.

LENKERSDORF, Carlos. Aprender a escuchar, enseñanzas maya-tojolabales. México: Plaza y Valdes editores, p. 2008.

MICHI, Norma; DI MATTEO, Álvaro Javier; VILA, Diana. "Movimientos populares y procesos formativos". Revista Polifonías, Departamento de Educación UNLu, Ano 1, n.1, p. 22-41, 2012.

MICHI, Norma. Movimientos populares y educación, un campo de estudio y de acción, 2019a. [texto en proceso de edición]

MICHI, Norma. Reflexiones sobre prácticas de producción colectiva de conocimientos o pequeñas contribuciones a una agenda de trabajo. Investigación Militante, en Melgarejo. In: MELGAREJO, Patrícia Medina (Coord.). Pedagogías del Sur en Movimiento. Veracruz: Universidad Veracruzana, Instituto de Investigaciones en Educación, 2019b, p. 72-89.

MICHI, Norma; DI MATTEO, Javier. Los movimientos como espacios de democracia sustantiva y de construcción de subjetividades. 2019 [en proceso de edición]

PORTO GONCALVES, Carlos Walter. Geo-grafías. Movimientos sociales, nuevas territorialidades y sustentabilidad. México: Siglo XXI, 2001

RETAMOZO, Martín. "Movimientos sociales, política y hegemonía en Argentina". Polis [En línea], n. 28, 2011, Puesto en línea el 13 abril 2012, consultado el 19 octubre 2012. URL: http://polis.revues.org/1249; DOI : 10.4000/polis.1249 
RETAMOZO, Martín. Cambios estructurales y prácticas de movilización política en Argentina. Dos ciclos políticos en perspectiva (1989-2002 y 2003-2015). Papel político, v. 23, n. 2, p. 1-19, 2018.

TEUBAL, Miguel. Soja y agronegocios en la Argentina: la crisis del modelo. Revista Lavboratorio. Cambio Estructural y Desigualdad Social (CEyDS) / Facultad de Ciencias Sociales, UBA. Ano 10, n. 22, p.5-12, 2008.

SEGATO, Rita Laura. El sexo y la norma: frente estatal, patriarcado, desposesión, colonialidad. Revista Estudos Feministas, Florianópolis, v. 22, n. 2, p. 593-616, maio-agosto/2014

TAPIA, Luis. Movimientos sociales, movimientos societales los no lugares de la política". In: TAPIA, Luis. Política Salvaje. La Paz: Coediciones, CLACSO, Muela del Diablo, Comunas, 2008.

WILLIAMS, Raymond. Marxismo y literatura. Barcelona: Edit. Península, 1980.

Artigo recebido em: fevereiro/2021

Artigo aceito em: julho/2021 